\title{
Fire Plume Ejected from an Opening in Unconfined Space Part 1 Experimental Outline
}

\author{
Tomoaki Nakao ${ }^{1}$, Akito Yanagisawa ${ }^{1}$, Akihide $\mathrm{Jo}^{1}$, Kaoru Wakatsuki ${ }^{1}$ and Yoshifumi Ohmiya ${ }^{1}$ \\ ${ }^{1}$ Tokyo University of Science
}

Keywords : Compartment Fire, Scale Model Experiment, Pyrolysis Rate

\section{BACKGROUND AND OBJECTIVE}

When a fire occurs in a building, there becomes a risk of fire spreading to upper floors through openings such as windows and doors. A fire plume ejected from an opening is an important factor to consider in order to prevent damage from a spreading fire. It is possible that the behavior of the fire plume and/or flame ejected from an opening varies depending on the spatial structure of the building. As the modern spatial structure of a building becomes taller, more overcrowded and more complicated, the dangers associated with a fire become greater. According to the assorted data per building structure with respect to the path of the fire spreading to other rooms, in most fire resistive buildings $40 \%$ of the paths involve "spreading through an opening". The "fire spreading path to other rooms" can be identified as the most vulnerable area that causes human injury and property damage.

In general, the flame behavior can be determined by the shape of the compartment and the openings, and the total heat release rate of the flammable materials in the compartment. It is presumable that the fire plume is ejected from an opening as a result of the reaction of the unconsumed flammable gas inside the compartment with the oxygen outside the compartment. Therefore, in order to understand the behavior of the fire plume ejected from an opening, it is necessary to determine the heat release rate (threshold limit) of the fire source when the flame was ejected. It is very important for fire safety design to determine the ejected threshold conditions of the heat release rate in order to understand the risks of the fire spreading and to minimize damage.

In the past research [1-5], the ejected threshold condition of the heat release rate is considered to be dependent on the size of the compartment and/or the opening factor. However, even with Yokoi's experiment [6] conducted in the past, the influence of external factors such as the adjacent wall of the opening (e.g. wing wall and opposed wall) has not been taken into account.

Therefore, from the perspective of fire spreading prevention, by focusing on the wall in the vicinity of the opening, which is a common condition in areas where buildings are overcrowded, an experiment was conducted to determine the ejected threshold condition of the heat release rate when the opposed wall and wing wall were installed in the vicinity of an opening. Additionally, this experiment used a small-sized compartment model to quantitatively understand how the position of the walls and opening factor would affect the ejected threshold condition of the heat release rate. 


\section{EXPERIMENTAL SUMMARY}

\subsection{Experimental equipment}

The experimental equipment shown in Figure 1 is comprised of a compartment, opening, floor, wall surrounding the opening, wing wall in the vicinity of the opening end, opposed wall against the opening face, and gas burner. The wall is made of a ceramic board $0.04 \mathrm{~m}$ thick, and the joints are finished by heat-resistant adhesive. The fire compartment is a cube whose inside dimension is $0.5 \mathrm{~m}$. The distance between the wing wall and the opening end is $S$, and the distance between the opposed wall and the opening face is $D$. The wing wall or opposed wall (width $0.9 \mathrm{~m} \times$ height $1.8 \mathrm{~m}$ ) is installed in the vicinity of the compartment according to the experimental condition. The fuel of the fire source was propane and a gas burner was installed at the center of the compartment. The dimensions of the burner were $0.5 \mathrm{~m} \times 0.1 \mathrm{~m}$; however, the edge was covered depending on the experimental condition (e.g. $0.2 \mathrm{~m} \times 0.1 \mathrm{~m}$ ). Gas flow rate was controlled by a mass flow controller.

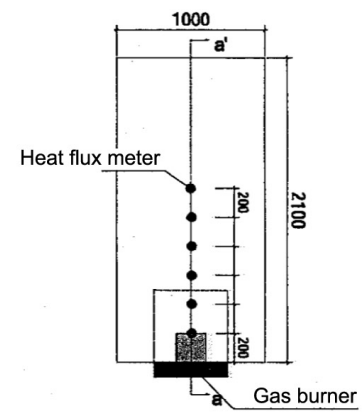

(a) Elevation plan (plane of compartment wall)

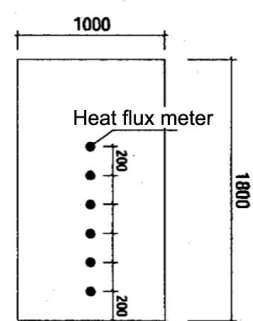

(b) Elevation plan (plane of opposed wall)

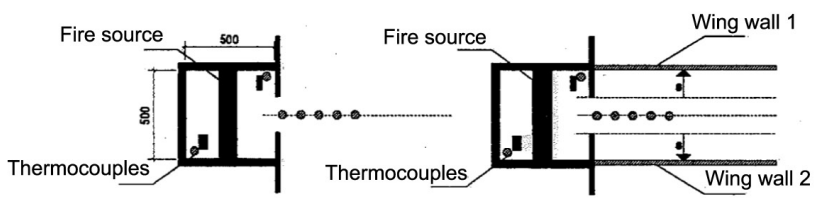

(c) Floor plan (open space)

(d) Floor plan (wing wall)

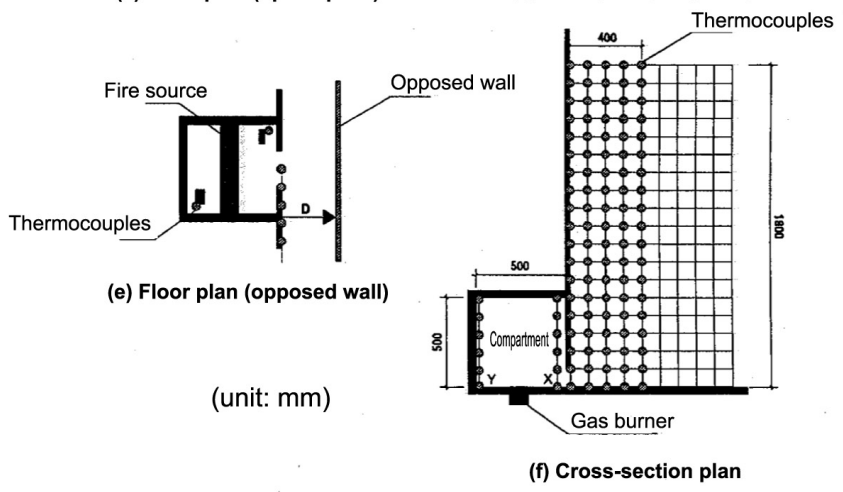

Figure 1 Experimental equipment and measurement points 


\subsection{Measurement parameters}

\section{a) Temperature distribution of the fire plume ejected from an opening}

In order to measure the temperature distribution of the fire plume ejected from an opening, K-type thermocouples $(\phi 0.32 \mathrm{~mm})$ were installed at $95(51 \times 19)$ points from the bottom end of the opening and placed on the steel lattice net $(0.1-\mathrm{m}$ intervals $)$ of dimensions of Width $0.9 \mathrm{~m} \times$ Height $1.8 \mathrm{~m}$. The net for the thermocouples was placed horizontal to the opening face and moved in intervals of $0.025 \mathrm{~m}, 0.05 \mathrm{~m}$, and $0.1 \mathrm{~m}$ to measure the temperature. By measuring the flame area at $0.025-\mathrm{m}$ intervals, the orbit of the trajectory (central axis of the ejected fire plume) was clarified.

\section{b) Compartment temperature}

In order to measure the temperature inside the compartment, the K-type thermocouples $(\phi 0.32 \mathrm{~mm})$ were placed on 2 corners, $X$ (front-right) and $Y$ (back-left), with 6 points each (12 points in total) at $0.16-\mathrm{m}$ intervals in the vertical direction. Temperature was measured at 2 -s intervals for $1 \mathrm{~min}$.

\section{c) Incoming heat flux to the wall above the opening (only condition for Table 2)}

The heat flux meters (MEDTHERM, Gardon Gage) were placed at 6 points with $0.2-\mathrm{m}$ intervals in the vertical direction from the bottom end (floor) of the opening and the measuring face was set toward the opposed wall.

\section{d) Incoming heat flux to the opposed wall (only condition for Table 2)}

The incoming heat flux to the opposed wall was measured with the heat flux meters placed at 6 points from the floor at $0.2-\mathrm{m}$ intervals in the vertical direction, and the meters were positioned facing the fire. The incoming heat flux to the opposed wall was measured at 2 -s intervals for $2 \mathrm{~min}$. 
Table 1 Experimental conditions (threshold of the fire plume ejected from an opening)

\begin{tabular}{|c|c|c|c|c|c|c|c|c|c|}
\hline \multirow{3}{*}{$\begin{array}{l}\text { Case } \\
\text { No. }\end{array}$} & \multicolumn{2}{|c|}{ Opening } & \multirow{2}{*}{$\begin{array}{c}\begin{array}{c}\text { Opening } \\
\text { factor }\end{array} \\
\mathrm{AH}^{1 / 2}\end{array}$} & \multicolumn{2}{|c|}{$\begin{array}{l}\text { Distance from } \\
\text { wing wall }(\mathrm{S})\end{array}$} & \multirow{2}{*}{$\begin{array}{l}\text { Distance } \\
\text { from } \\
\text { opposed } \\
\text { wall }(\mathrm{S})\end{array}$} & \multicolumn{2}{|c|}{ Fire source } & \multirow{3}{*}{ Floor * } \\
\hline & $\begin{array}{l}\text { Width } \\
\text { (B) }\end{array}$ & $\begin{array}{l}\text { Height } \\
\text { (H) }\end{array}$ & & 1 wing & 2 wings & & Width & Depth & \\
\hline & (m) & (m) & $\left(\mathrm{m}^{5 / 2}\right)$ & (m) & (m) & (m) & (m) & (m) & \\
\hline $1-1$ & \multirow{8}{*}{0.2} & \multirow{8}{*}{0.2} & \multirow{8}{*}{0.0179} & \multirow{3}{*}{$\infty$} & \multirow{3}{*}{$\infty$} & \multirow{3}{*}{$\infty$} & 0.2 & 0.1 & $\circ$ \\
\hline $1-2$ & & & & & & & \multirow{7}{*}{0.5} & \multirow{7}{*}{0.1} & $\circ$ \\
\hline 1-3 & & & & & & & & & $x$ \\
\hline $1-4$ & & & & 0 & - & - & & & $\circ$ \\
\hline $1-5$ & & & & 0.05 & - & - & & & $\circ$ \\
\hline 1-6 & & & & - & 0 & - & & & $\circ$ \\
\hline $1-7$ & & & & - & - & 0.1 & & & $\circ$ \\
\hline $1-8$ & & & & - & - & 0.3 & & & o \\
\hline $1-9$ & \multirow{8}{*}{0.2} & \multirow{8}{*}{0.1} & \multirow{8}{*}{0.0063} & \multirow{3}{*}{$\infty$} & \multirow{3}{*}{$\infty$} & \multirow{3}{*}{$\infty$} & 0.2 & 0.1 & 0 \\
\hline $1-10$ & & & & & & & \multirow{7}{*}{0.5} & \multirow{7}{*}{0.1} & $\circ$ \\
\hline $1-11$ & & & & & & & & & $x$ \\
\hline $1-12$ & & & & 0 & - & - & & & o \\
\hline $1-13$ & & & & 0.05 & - & - & & & $\circ$ \\
\hline $1-14$ & & & & - & 0 & - & & & $\circ$ \\
\hline $1-15$ & & & & - & - & 0.1 & & & $\circ$ \\
\hline $1-16$ & & & & - & - & 0.3 & & & $\circ$ \\
\hline $1-17$ & \multirow{8}{*}{0.1} & \multirow{8}{*}{0.2} & \multirow{8}{*}{0.0089} & \multirow{3}{*}{$\infty$} & & & 0.2 & 0.1 & 0 \\
\hline $1-18$ & & & & & $\infty$ & $\infty$ & \multirow{7}{*}{0.5} & \multirow{7}{*}{0.1} & $\circ$ \\
\hline $1-19$ & & & & & & & & & $x$ \\
\hline $1-20$ & & & & 0 & - & - & & & $\circ$ \\
\hline $1-21$ & & & & 0.05 & - & - & & & $\circ$ \\
\hline $1-22$ & & & & - & 0 & - & & & $\circ$ \\
\hline $1-23$ & & & & - & - & 0.1 & & & $\circ$ \\
\hline $1-24$ & & & & - & - & 0.3 & & & $\circ$ \\
\hline
\end{tabular}

$\circ$ : With floor, $\times$ : No Floor 
Table 2 Experimental conditions (understanding the behavior of the ejected fire plume taking into account the opposed wall)

\begin{tabular}{|c|c|c|c|c|c|}
\hline \multirow{2}{*}{ Case No } & \multicolumn{2}{|c|}{ Opening } & \multirow{2}{*}{$\begin{array}{c}\text { Dist. from } \\
\text { opposed wall (S) }\end{array}$} & \multirow{2}{*}{$\begin{array}{c}\text { Opening factor } \\
\mathrm{AH}^{1 / 2}\end{array}$} & \multirow{2}{*}{$\begin{array}{c}\text { HRR, } Q \\
1800 \mathrm{AH}^{1 / 2}\end{array}$} \\
\hline & W (B) & $\mathrm{H}(\mathrm{H})$ & & & \\
\hline & $(\mathrm{m})$ & (m) & $(\mathrm{m})$ & $\left(\mathrm{m}^{5 / 2}\right)$ & $\mathrm{kW}$ \\
\hline $2-1$ & \multirow{10}{*}{0.2} & \multirow{10}{*}{0.2} & 0.1 & \multirow{10}{*}{0.0179} & \multirow{10}{*}{32.2} \\
\hline $2-2$ & & & 0.125 & & \\
\hline $2-3$ & & & 0.15 & & \\
\hline $2-4$ & & & 0.175 & & \\
\hline $2-5$ & & & 0.2 & & \\
\hline $2-6$ & & & 0.3 & & \\
\hline $2-7$ & & & 0.4 & & \\
\hline $2-8$ & & & 0.5 & & \\
\hline $2-9$ & & & 0.7 & & \\
\hline $2-10$ & & & 0.8 & & \\
\hline $2-11$ & \multirow{7}{*}{0.3} & \multirow{7}{*}{0.15} & 0.1 & \multirow{7}{*}{0.0179} & \multirow{7}{*}{32.2} \\
\hline $2-12$ & & & 0.125 & & \\
\hline $2-13$ & & & 0.15 & & \\
\hline $2-14$ & & & 0.175 & & \\
\hline $2-15$ & & & 0.2 & & \\
\hline $2-16$ & & & 0.3 & & \\
\hline $2-17$ & & & 0.4 & & \\
\hline $2-18$ & \multirow{7}{*}{0.39} & \multirow{7}{*}{0.13} & 0.1 & \multirow{7}{*}{0.0179} & \multirow{7}{*}{32.2} \\
\hline $2-19$ & & & 0.125 & & \\
\hline $2-20$ & & & 0.15 & & \\
\hline $2-21$ & & & 0.175 & & \\
\hline $2-22$ & & & 0.2 & & \\
\hline $2-23$ & & & 0.3 & & \\
\hline $2-24$ & & & 0.4 & & \\
\hline $2-25$ & \multirow{9}{*}{0.13} & \multirow{9}{*}{0.26} & 0.1 & \multirow{9}{*}{0.0179} & \multirow{9}{*}{32.2} \\
\hline $2-26$ & & & 0.125 & & \\
\hline $2-27$ & & & 0.15 & & \\
\hline $2-28$ & & & 0.175 & & \\
\hline $2-29$ & & & 0.2 & & \\
\hline $2-30$ & & & 0.3 & & \\
\hline $2-31$ & & & 0.4 & & \\
\hline $2-32$ & & & 0.5 & & \\
\hline $2-33$ & & & 0.6 & & \\
\hline $2-34$ & \multirow{9}{*}{0.1} & \multirow{9}{*}{0.31} & 0.1 & \multirow{9}{*}{0.0179} & \\
\hline $2-35$ & & & 0.125 & & \\
\hline $2-36$ & & & 0.15 & & \\
\hline $2-37$ & & & 0.175 & & \\
\hline $2-38$ & & & 0.2 & & 32.2 \\
\hline 2-39 & & & 0.3 & & \\
\hline $2-40$ & & & 0.4 & & \\
\hline $2-41$ & & & 0.5 & & \\
\hline $2-42$ & & & 0.6 & & \\
\hline
\end{tabular}




\subsection{Experimental procedure and conditions}

\subsubsection{Dependency of threshold limit of heat release rate on opening factor}

After specifying the opening dimension, fire source and wall positions, a fire was ignited by supplying propane gas to the burner. After confirming that the temperature inside the compartment was steady, the heat release rate was gradually increased, and then the heat release rate was recorded when the fire plume was ejected from the opening.

After confirming the fire plume was ejected, the heat release rate was gradually lowered, and then the heat release rate was recorded when the fire plume was no longer ejected from the opening. Their mean values were determined as the threshold limit of heat release rate. As a note, the presence of the fire plume was determined by visual observation.

There were three different opening conditions: square (Width $0.2 \mathrm{~m} \times$ Height $0.2 \mathrm{~m}$ ), rectangular/horizontally long (Width $0.2 \mathrm{~m} \times$ Height $0.1 \mathrm{~m}$ ) and rectangular/vertically long (Width $0.1 \mathrm{~m} \times 0.2 \mathrm{~m}$ ). Table 1 shows the experimental conditions when the threshold of the ejected fire plume was verified.

\subsubsection{Understanding the behavior of the fire plume taking into account the opposed wall}

The pyrolysis rate of wood was set to $0.1 A H^{1 / 2}[\mathrm{~kg} / \mathrm{s}]$ so that the heat release from the burner could be simulated as the heat of combustion of the wood. By assuming that the flammable gas inside the compartment and inside the ejected fire plume burns completely, the value of the heat release rate, $1800 A H^{1 / 2}[\mathrm{~kg} / \mathrm{s}]$, was given, which is the product of the heat of combustion of wood $18000[\mathrm{~kJ} / \mathrm{kg}]$ and $0.1 A H^{1 / 2}[\mathrm{~kg} / \mathrm{s}]$.

In order to facilitate the comparison of the ejected fire plume behavior, the heat release rate $Q_{\text {bur }}$ was kept constant by making the temperature factor $A H^{1 / 2}[\mathrm{~kg} / \mathrm{s}]$ at the opening the same, and the ejected fire plume behavior was assessed by using parameters, which represents the difference of the opposed wall condition from the opening condition.

There are 5 different dimensions of the opening ( 1 type of square shape, 2 types of rectangular shape/longer horizontally and 2 types of rectangular/longer vertically) as described in Table 2.

\section{REFERENCES}

1. Hagglund B., Jansson R. and Onnermark B., "Fire development in residential rooms after ignition from nuclear explosions", FOA Report C 20016-D6 (A3), 1974

2. Jansson R. and Onnermark B, "Fire development in residential rooms after ignition from nuclear explosions[R]". FOA Report C20445-A3, 1982

3. Hasemi Y., "Properties of external flames from an opening of room fire", Symposium of Safety Engineering, pp. 215-218, 1993 (in Japanese) 
4. Ohmiya Y. and Hori Y., "Properties of External Flame taking into Consideration Excess Fuel Gas Ejected from Fire Compartment", Journal of architecture, planning and environmental engineering. Transactions of AIJ, No.545, pp. 1-8 (in Japanese)

5. Lin C., Sugahara S. and Naruse T., "Emergence-limit of Flames form a Compartment -A Thought on Some Experimental Results-", Journal of structural and construction engineering. Transactions of AIJ, No.419, pp.163-168, 1991 (in Japanese)

6. Yokoi, S., Study on Fire-Propagation by Spouting Flame at Buildings and its Defensive Measures (Doctoral thesis) (in Japanese) 